\title{
VISUALIZING DAILY ON-SITE SPACE USE
}

\author{
Audrey M. Bascoul ${ }^{1}$ and Iris D. Tommelein ${ }^{2}$
}

\begin{abstract}
Visual Management (VM) is integral to the lean philosophy. For example, an Andon makes a light flash in the case of a deviation in the process of assembly or in the product assembled, a Kanban triggers the production of units in order to fill a customer's demand, shadow boards used in 5S help workers to locate their tools easily. What is lacking in the construction industry is simple, cost- and time-effective programs that support the understanding of the work schedule, foster transparency in daily coordination of work space among subcontractors, and facilitate production control. To address these needs, this paper presents a space scheduling program called LOSite developed for a case study project, and demonstrates that space use visualization is possible on large scale projects and can be inexpensive yet worthwhile using. The researchers prototyped LOSite in one week to help visualize the work being done during a project's interiors phase. LOSite was tested over the course of a month. Limitations to the full adoption of LOSite by the team are discussed in this paper.
\end{abstract}

Keywords: Lean construction, Visual Management, space use, space scheduling, subcontractor coordination.

\section{INTRODUCTION}

To remain competitive and satisfy clients, the construction industry must deliver projects faster. Decoupling activities so that they can be run simultaneously, and crashing the schedule by increasing manpower are strategies adopted to decrease project durations. Those strategies force more trades and workers to share the limited project space. However, increasing the density of workers on the project site poses a safety risk and a production control challenge if not thoughtfully managed.

This paper presents a program developed to help the project team visualize the work being done by each trade in the interiors phase. The next sections describe how this work builds upon previous research in Visual Management and space use modelling.

\section{Visual Management (VM)}

Visual Management (VM) is defined as a management system that increases the performance of an organization by stimulating human senses (Greif 1991, Liff and Posey 2004, Tezel 2009). VM has been in use in multiple sectors such as manufacturing, healthcare, transportation. Among them, the Toyota Production System integrates various visual tools (Liker and Meier 2005).

$1 \quad$ PhD candidate, Civil and Environmental Engineering Department, Univ. of California, Berkeley, CA 94720-1710, USA, AudreyBascoul@berkeley.edu

2 Professor, Civil and Environmental Engineering Department, and Director of the Project Production Systems Laboratory (p2sl.berkeley.edu), 212 McLaughlin Hall, Univ. of California, Berkeley, CA 947201712, USA, tommelein@berkeley.edu 
In the development of standards, visual controls help to: (1) create alignment from the entire organization on the agreed standards and (2) enable workers and supervisors to recognize deviations from these standards. Once standards are consistently met, the organization can set higher standards as part of their continuous improvement cycle.

Adopting Tezel et al.'s (2015) comprehensive taxonomy of VM programs in construction, LOSite belongs to the "production control" category. Production control systems are represented by a level of: (1) initial planning, (2) lookahead planning, and (3) commitment planning (Ballard and Howell 1997). Although the project studied in this paper was delivered using traditional project management methods, the intent behind the development of the VM program was to visualize daily space use by construction trades and thereby facilitate production control. On projects using lean planning methods, trade partners could use daily space use maps to develop a shared understanding with the GC about their respective processes space needs in order to ensure continuous work flow.

\section{SPACE USE}

Riley and Sanvido (1995) distinguished 12 types of spaces on construction projects, including material path, staging area, and work areas. This paper will focus on work areas.

Time-space conflicts of work areas occur when two concurrent activities have overlapping space requirements. Time-space conflicts (e.g., trade stacking) are a pet peeve of project teams: they negatively impact productivity, they create safety hazards, they fuel adversarial relationships on the construction site, and they increase the likelihood of trade damage as reported in construction claims.

Time-space conflicts are more likely to occur in spaces where the so-called work density is high, that is: where the quantity of work (in labor-hours) per unit area and unit of time is large. Frandson et al. (2015) write that work density refers to "the situation in an area on site based on (1) the amount of work required by one trade in a particular area, (2) the trade's crew sizing and capabilities, and (3) the trade's means and methods (e.g., when prefabricating off site, the work density decreases)".

Different approaches to reduce and eliminate occurrences of time-space conflicts exist. Among them, two are relevant to this paper: (1) layout planning and (2) space scheduling. However, a fine boundary exists between the two.

Both space scheduling and layout planning are complex due to the nature of space itself: space is not a scalar variable (Tommelein and Zouein 1992) whereas other resources are (e.g., time and cost). The fine difference between space scheduling and layout planning lies in the type of relationship between space and schedule. In layout planning, that relationship is unidirectional: space requirements stem from the schedule (Tommelein and Zouein 1992). In space scheduling, that relationship is bidirectional: space requirements influence the schedule and vice versa (Tommelein and Zouein 1992). In other words, space scheduling consists in "allocating space to resources governed by a construction schedule, and conversely, changing the schedule when space availability is inadequate" (Tommelein and Zouein 1993).

Researchers have developed layout and space scheduling programs for this purpose over the last 20 years or so, while gradually augmenting dimensions $(2 \mathrm{D}, 3 \mathrm{D}, 4 \mathrm{D} \ldots)$ as technology allowed it. Examples are: CORELAP (Moore 1971), ALDEP (Seehof 1971), CONSITE (Hamiani 1987), MovePlan (Tommelein and Zouein 1992), SCaRC (Thabet 1992), SEED-Layout (Flemming and Chien 1995), ArcSite (Cheng and O'Connor 1996), 4DWorkplanner (Akinci and Fischer 2000), and others. More recent and commercially 
available software applications include: Synchro, Autodesk Navisworks, Bentley Navigator, to name a few.

\section{PRoject DEscription}

\subsection{Project Overview}

The project included demolishing existing buildings and constructing a $41,000 \mathrm{~m}^{2}(430,000$

$\mathrm{ft}^{2}$ ) office building. The building consisted of 3 levels: a parking level, a first level, and a green roof. The project broke ground in October 2013 and lasted 16 months. The researchers joined the GC's interiors team in February 2014 and conducted "action research" on site until March 2015.

With respect to the design of the interiors, the first level resembled an immense warehouse composed of: (1) an open space called "the Big Room" in which employees can work collaboratively, and (2) about 100 clusters of rooms (called "pods") scattered across the open space. Each pod comprised between 2 and 10 rooms and is more-or-less unique, which contributed to the project's complexity.

\subsection{Project Location Breakdown Structure}

Although the term Location Breakdown Structure (LBS) was not used on the project, this paper employs the term for clarity. The LBS for this project changed per project phase, and the preference for each LBS varied across stakeholders. With respect to the interiors, team members juggled with two LBSs: the zone-LBS and the area-LBS. The coexistence of 2 LBSs created confusion among subcontractors, project engineers, and contributed to the project's complexity. On the one hand, the zone-LBS comprised 4 zones separated by the seismic joints of the building. The BIM implementation team used this LBS and contract documents required subcontractors to submit their 3D model per this LBS. On the other hand, the area-LBS divided the site in 5 areas of approximately the same size. The GC and the subcontractors preferred working in this LBS, because the Architect had used it to produce the 2D floor plans (Figure 1). In both LBSs, areas or zones contained a combination of a portion of collaborative open space, some pods, and some mezzanines with additional rooms and stairs.

\subsection{Production Planning on the Project}

The GC created the master schedule in the preconstruction phase, and used the critical path method to track project progress. The GC screened activities in a 3-week rolling lookahead schedule created in Primavera (P6) on a weekly basis, and from that schedule, assigned subcontractors tasks to perform in the coming week. The purpose of using P6 on this project was twofold: (1) meet the contract requirements and (2) manage production. The GC distributed the 3-week schedule to subcontractors in weekly meetings. The project did not use the Last Planner System.

In the lookahead schedule, the GC further grouped activities per pod. For example, the lower half of Figure 2 shows pod 1.93 that comprised 6 small conference rooms and 3 cozy rooms. Additionally, a typical activity line in the schedule included: the location (aka. a pod number), name, duration, start date, and finish date, but not the name of the subcontractor to which the activity was assigned. Examples of activities were: "Frame walls and ceilings," "Wall/ceiling rough in and backing," and "Pre-test and state inspection." This was the finest level of granularity at which activities were described. 

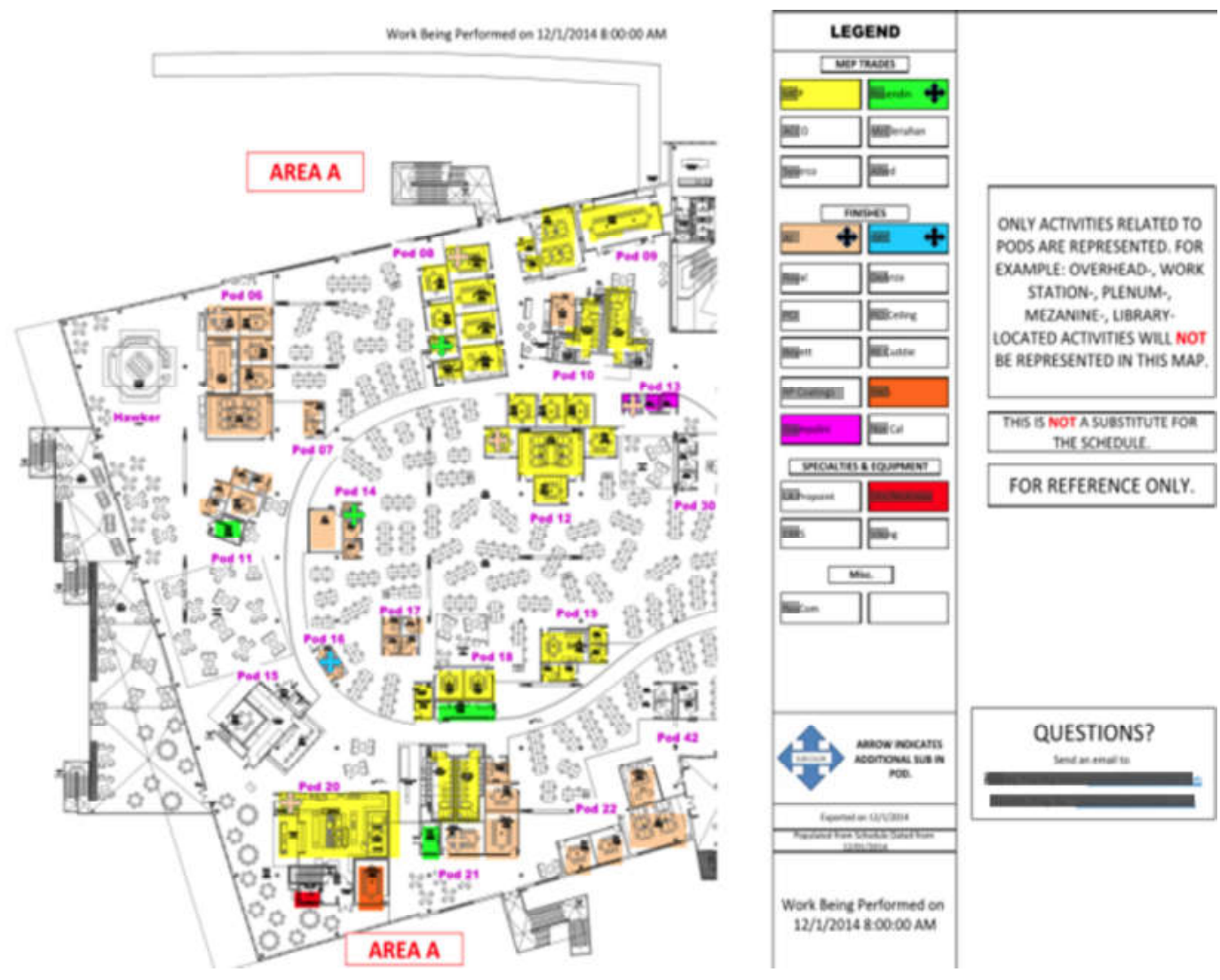

Figure 1: Output of LOSite for area A

\begin{tabular}{|c|c|c|c|c|}
\hline & Activity Name & \begin{tabular}{|c|} 
Original \\
Duration
\end{tabular} & Start & Finish \\
\hline 2912 & Install hoistway piping / Wiring & 4 & 06-Nov-14 A & 14-Nov-14 A \\
\hline 2913 & Insatil cab finishes & 3 & 12-Nov-14 A & 14-Nov-14 A \\
\hline 2914 & Pre test \& state inspection & 5 & 15-Dec-14 & 19-Dec-14 \\
\hline \multicolumn{2}{|c|}{1.93 (6 small, 3 cozy) } & 96 & 20-Aug-14 A & 06-Jan-15 \\
\hline 2916 & Frame Walls and Ceilings & 4 & 20-Aug-14 A & 21-Aug-14 A \\
\hline 2917 & Wall / Ceiling Rough-ins \& Backing & 3 & 21-Aug-14 A & 26-Aug-14 A \\
\hline
\end{tabular}

Figure 2: 3-week rolling lookahead schedule, line item example

\subsection{Consequences of Production Planning on the Project}

Since the subcontractor's name had not been populated for any activity, the P6 schedule could not be filtered by subcontractor prior to its distribution in weekly meetings. As the full 3-week schedule was handed out to the subcontractors every week, the large number of activities made it difficult for the subcontractors to (1) calculate and plan for the manpower they needed for the following week, and (2) relay instructions to their own crews on what work to do and where. If subcontractors had difficulty planning for their own crew sizes, how could they commit to weekly work plans? Poor schedule communication was experienced onsite: how could the GC rule in favor of one subcontractor or another when the two claimed work in the same location at the same time? Not surprisingly, trades had difficulty anticipating and visualizing space handoffs with the preceding and the following trades. They also were concerned with sharing work space with other trades in areas with large work density (e.g., pods), where congestion appeared to be inevitable without space scheduling. Furthermore, progress control was 
also difficult on the GC's side as superintendents had no practical means of checking every day whether subcontractors had allocated enough resources to complete the work they were assigned.

As a result, subcontractors expressed the need for a better way to communicate the schedule. The researchers tried to achieve this by programming a space use visualization program, as described next.

\section{LOSITE TO VISUALIZE SPACE USE}

\subsection{Program Design and Methodology}

LOSite was initially designed to better communicate the schedule to the subcontractors than what the 3-week rolling schedule extracted from P6 did. Concerns raised by subcontractors indicated that LOSite should help them: (1) identify where they had work to complete for a given day, (2) plan for the manpower they needed for the following week, and (3) identify space-time conflicts resulting from over-allocation of space.

Although subcontractors had been identified as the main customers to LOSite, the GC also benefited from using it, as explained in the Results section.

We followed Deming's Plan Do Check Act (PDCA) cycle (action research) for the design of LOSite. The planning phase served to determine the conditions of satisfaction (COS) for LOSite. COS were then used to check results against expectations in the checking phase of the cycle. COS required LOSite to: (1) make the schedule visual to facilitate the conversation around planning work, (2) be easy to use and time-effective, (3) not require training to use, and (4) not rely on significant make-ready work. Thus, modifying the current schedule was out of the scope of this research.

Frandson and Tommelein's (2014) work on the \$3-million dollar retrofit of an urgent care center guided LOSite design for this project. However, their project and this project differ significantly. First, their project involved takt time, which this project did not. Second, theirs was substantially smaller than ours: scope, size, number of subcontractors, etc. which entailed differences in projects complexity. The next section describes the nature of the challenges faced when developing and using LOSite, and how those challenges were overcome.

\subsection{How the Daily Space-Use Visualization Program Works}

LOSite was written in Visual Basic using Microsoft Excel 2014. The workbook consisted of 7 spreadsheets. Two spreadsheets contained the information exported from P6 and 5 spreadsheets contained the interiors 2D drawing of each of the 5 areas (A to E).

The level of detail the researchers chose to depict graphically on their map aimed at addressing criticism on previous research. Frandson and Tommelein (2014) had used simple rectangles on a white background to represent work zones on site, color coded by trade for each day, but the lack of architectural detail caused trades to lose their bearing. To alleviate this problem, the researchers used the actual 2D drawings to represent space use in LOSite.

To do so, the researchers overlaid the Excel spreadsheets with the floor plans. In each of the 5 spreadsheets, they renamed the range of cells overlaying the pod with its corresponding pod number. Since activities were listed per pod number in the schedule, LOSite could identify which activity had to be performed in a given cell thanks to the cell's name. 
In the same workbook, the 3-week schedule was copied-and-pasted as such on a spreadsheet. LOSite read each line of the copied schedule to check whether or not the activity was occurring on the given date (the given date was entered in LOSite by the user). If so, LOSite identified the corresponding subcontractor. The researchers created a keyword database per subcontractor so that LOSite could identify the subcontractor to assign to an activity depending on the words used in the activity's description.

Each subcontractor was represented by a color. When the subcontractor was identified for an activity, LOSite read the activity location as written in the schedule, and colored-up the corresponding range of cells that had a matching name. LOSite also colored-up the corresponding name of the subcontractor in the legend. Then, LOSite jumped to the next line in the copied schedule and iterated through the process as described.

In total, the development of LOSite took 2 weeks.

\subsection{User Experience}

The researchers added an interface to the workbook to facilitate the use of LOSite. This section describes the steps taken to generate the daily space schedule. The first 2 were necessary in case of a schedule update. Otherwise, the user experience started at step 3.

1. Import the schedule. The schedule was developed with P6. P6 allows users to export the schedule in.xls format. The schedule was then copied, and pasted into the Excel workbook.

2. Update the workbook (automated with Visual Basic). This step filtered out activities that did not need to be represented on the daily space schedule. Those activities included exterior activities and activities not tied to a pod number.

3. Select the area to color-up. Both the architectural drawings and the 3-week schedule were divided to show work in each of five areas A to E. The user could, for a given date, either generate the daily space schedule for a single area or generate the daily space schedule for all areas.

4. Enter the date for schedule generation and the date for the last schedule update.

The LOSite program then generated the daily space schedule for a given day for all 5 areas in 5 minutes or less.

\subsection{Output}

Figure 1 illustrates the output generated by LOSite. It shows the space use for area A on December 1, 2014. The legend is divided into four categories: (1) MEP trades, (2) Finishes, (3) Specialties and Equipment, (4) Miscellaneous. On the example shown, 7 subcontractors were working in the area on that day.

LOSite displayed an arrow icon on the map when two trades were working in the same location on the given day. The color of the arrow is the color of the second subcontractor sharing the space, the first subcontractor being indicated by the color of the room itself. LOSite also displayed the arrow icon in the legend next to the second subcontractor that shared the space. Note that the presence of an arrow did not necessarily imply space interference. For example, in Pod 16 the drywall subcontractor shared the space with the casework subcontractor. In this case, the drywall subcontractor could be taping the exterior of the pod, and be done inside the pod, and the casework subcontractor could be hanging plywood panels inside the room. On the project, the GC analysed and eliminated time-space conflicts on a case-by-case basis after the generation of the maps and before handing the maps to the subcontractors. 


\section{RESULTS AND LESSONS LEARNED}

Over the course of 1 month, the researchers generated daily space use maps every Monday for the current week, and made them available to the 5 superintendents and 22 foremen ( 1 per trade) on their tablets. Although the COS set for LOSite were met, the GC did not take full ownership of LOSite and stopped using it after the researcher left the project for a few weeks.

Discussion with the subcontractors and the superintendents revealed some drawbacks to LOSite: (1) the open space area was not colored-up by LOSite, and (2) the name of the activity to perform in a room was not indicated on the maps.

The first drawback stressed the importance of defining an LBS that facilitates production planning, as well as the importance of precisely allocating an area to each activity in the schedule, which was not done for the open space in which multiple activities were listed as happening concurrently. Logistically, this was not a problem since the open space was large enough in each zone to allow multiple subcontractors to work concurrently and hence the work density was small. However, project progress was more difficult to assess in this area.

The second drawback was brought up by the GC even though the GC was initially not the intended audience for LOSite. Yet, the GC used LOSite for different purposes: (1) check the quality of the schedule, (2) schedule backlog activities in unassigned rooms, and (3) track resource commitments from subcontractors. Regarding (1) and (2), when a room was not colored-up on a given day, no activity had been scheduled to take place there. It either meant that the schedule was incorrect (i.e., an activity had been overlooked, a finishto-start relationship omitted, etc.) or that a backlog activity could be assigned. Regarding (3), superintendents were using the colored maps to check that subcontractors were actually working in all of their assigned rooms on a given day.

The case study shows that space use visualization can benefit both the subcontractors and the GC. For the subcontractors, planning for manpower on large projects is facilitated when the quantity of the work is conveyed in area quantities. Manpower is also dependent on how scattered the work to be done is on the project site, which was also captured in the maps. For the GC, space use visualization helped to avoid time space interferences and catch mistakes in the schedule. Because LOSite could not capture space use in areas that were not precisely delimited (see uncolored space in Figure 1), it emphasized the importance of the LBS for production control. Ill-defined work areas were a symptom of lack of work flow coordination from the GC. It also enabled superintendents to track resource commitments from subcontractors.

\section{CONCLUSION}

Further research is needed to understand how one could make the project team consistently use LOSite throughout the project. Other questions are to be addressed, e.g., to which extent (if any) does visualization of site space use impact handoff reliability between trades? Finally, LOSite should be tested on other projects to gain robustness.

\section{ACKNOWLEDGMENTS}

We sincerely thank Company $\mathrm{X}$ and the entire project team for allowing us to conduct action research on a highly complex project. This research is funded in part by gifts made to the Project Production Systems Laboratory (P2SL) (http://p2sl.berkeley.edu). All support 
is gratefully acknowledged. Any opinions, findings, conclusions, or recommendations expressed in this paper are those of the writers and do not necessarily reflect the views of the P2SL members.

\section{REFERENCES}

Akinci, B. and Fischer, M. (2000). "An Automated Approach for Spaces Required by Construction Activities." Constr. Cong. VI, Orlando, FL, Feb. 20-22.

Ballard, G., and Howell, G. (1997). "Shielding Production: An Essential Step in Production Control." ASCE J. Constr. Eng. Mgmt., 124(1), pp. 11-17.

Cheng, M.Y. and O'Connor, J.T. (1996). "ArcSite: Enhanced GIS for construction site layout." ASCE J. Const. Eng. Mgmt., 122(4), pp. 329-336.

Flemming, U. and Chien, S.-F. (1995). "Schematic Layout Design in SEED Environment." ASCE J. Arch. Eng., pp. 162-169.

Frandson, A.G. and Tommelein, I.D. (2014). "Development of a Takt-Time Plan: A Case Study." ASCE Proc. Constr. Res. Cong. 2014, Atlanta, GA, May 19-21, pp. 1646-1655.

Frandson, A.G., Seppänen, O., and Tommelein, I.D. (2015). "Comparison Between Location Based Management and Takt Time Planning." Proc. 24th Ann. Conf. IGLC, Boston, MA, July.

Greif, M. (1991). The Visual Factory: Building Participation Through Shared Information. Portland, OR: Productivity Press.

Hamiani, A. (1987). CONSITE: A Knowledge-Based Expert System Framework for Construction Site Layout. PhD Diss., University of Texas, Austin, TX.

Liff, S. and Posey, P.A. (2004). Seeing is Believing. NYC, NY: Amacom, 272 pp.

Liker, L. and Meier, D. (2005). The Toyota Way Fieldbook, NY, NY: Mc Graw Hill Education, $288 \mathrm{pp}$.

Moore, J.M. (1971). "Computer Program Evaluates Plant Layout Alternatives." J. Ind. Eng., 3(8), pp. 19-25.

Riley, D.R. and Sanvido, V.E. (1995). "Patterns of Construction-Space Use in Multistory Buildings." ASCE J. Constr. Eng. Mgmt., 121(4), pp. 464-473.

Seehof, J.M. and Evans, W.O. (1971). "Automated Layout Design Program." J. Ind. Eng., 18(12), pp. 690-695.

Tezel, A. and Koskela, L. (2009). "Visual Management - A General Overview." 5th Intl. Conf. on Constr. in the 21st Century (CITC-V), Istanbul, Turkey, May 20-22.

Tezel, A., Koskela, L., Tzortzopoulos, P., Formoso, C.T., and Alves, T. (2015). "Visual Management in Brazilian Construction Companies: Taxonomy and Guidelines for Implementation." ASCE J. Mgmt. Eng., 14 pp.

Thabet, W.Y. (1992). A Space-Constrained Resource-Constrained Scheduling System for Multi-Story Buildings. PhD Diss., Virginia Polytech. \& State Univ., Blacksburg, VA, $644 \mathrm{pp}$.

Tommelein, I.D. and Zouein, P.P. (1992). "Activity-Level Space Scheduling." 9th Intl. Symposium on Automation and Robotics in Constr., Jun. 3-5, Tokyo, Japan.

Tommelein, I.D. and Zouein, P.P. (1993). "Interactive Dynamic Layout Planning." ASCE J. Constr. Eng. Mgmt., 119(2), pp. 266-287. 